\title{
Isikustatud õpe arvestab erinevusi: kas mõõdukalt tempereeritud utoopia?
}

\author{
Jaan Kõrgesaar ${ }^{\mathrm{a}}$ \\ ${ }^{a}$ Tartu Ülikool
}

Mitchell, D. (2017). Diversities in education: Effective ways to reach all learners. London, New York: Routledge.

Näe, taas üritatakse üksinda ühismeediaga võistelda, kandes oma märkmed ja mõtted ekraanile, et köita trükitud tulemus paberraamatuks. Oleks siis keskendutud ühele piisavalt kitsale valdkonnale, mida keskpärane surelik inimene suudaks jälgida. Oh ei! Oma järjekordses raamatus üritab rahvusvaheline menuautor ja -esineja David Mitchell, kes on kodus, Uus-Meremaal vastselt ordenikandjaks tõstetud, sünteesida eri valdkondades kogunenud teadmist koguni viie tunnuse alusel, mis eristavad inimrühmi ning mida peab õpilaste puhul arvestama ja arendama. Need viis teoses peatükki väärinud rühma on järgmised: bioloogiline ja sotsiaalne sugupool (ingl sex and gender); klassikuuluvus koos sotsiaal-majandusliku staatusega; rass ja rahvus (ingl ethnicity) koos kultuuriga; veendumused ja religioon; võimekus ja puue (ingl ability and disability). Seejuures ei pea autor religiooni teistega võrreldavalt kõikehõlmavaks riskiteguriks, kuivõrd usund piirab mõne riskirühma juurdepääsu vaid mõnes moslemiriigis. Ta möönab, et terviku haaramiseks napib temalgi jõudu, pakkudes joonisel 1.3 (lk 35) välja mitmekesisuse taksonoomia, milles kujutatakse peale osutatud viie erisustunnuse veel nelja: geograafiline asukoht, vanus, perekonna struktuur ja juurdepääs IKT-le. Enamgi, lk-1 299 loetletakse 19 tegurit (mööndes, et tegemist pole lõpliku loeteluga), mis põhjustavad inimeste erinevusi (mitmekesisust), olgu omaette või kombineeritult. Need 19 on evolutsioon, üleilmastumine, vaesus/viletsus, geograafiline asukoht, pärilikkus, neuroteadus, elukeskkonna allakäik, kultuurilised väärtused, konfliktid, õnnetused, sotsialiseerumine, poliitika, uusliberalism, tehnoloogia, ressursid, vanemlus, toidusedel, võõraviha, lõpuks haridus ise. Viimaks jätab autor ikka iga õpetaja otsustada, missuguseid õpilas(t)e arengujooni või erisusi tuleks esile tõstmise kaudu kiita, mida püüda kas sallida, eirata, kahandada või kõrvaldada (Mitchell, 2017, lk XVII). 
Autor seab raamatule kaks sihti. Esiteks, austada ja edendada mitmekesiste, st erinevate inimeste inimõigusi. Teiseks, arendada kaasavat ühiskonda ja globaalset kogukonda. Nende kahe sihi teenistusse asetab Mitchell $19 \mathrm{nn}$ läbivat väljavaadet (lk 4).

1. Mitmekesisusele tuleks läheneda õiglase (ümber?)jaotamise teooria (ingl theories of distributive justice) alusel.

2. Mitmekesisust tuleks näha ökoloogilises perspektiivis.

3. Mitmekesisuse tajumine varieerub ajas ja ruumis.

4. Keeruline on leida õige tasakaal samasuse ja mitmekesisuse vahel.

5. Käitumise ja poliitika nihkeid aitab selgitada huvide koondumine.

6. Mitmekesisuse ilmingud lõikuvad (ingl intersect) omavahel.

7. Mitmekesisusel on palju põhjusi.

8. Inimesed on pärilikult lähedased.

9. Tuleb silmas pidada mitmekesisuse evolutsioonilist perspektiivi.

10. Paljud erinevused on väikesed, olgugi et statistiliselt olulised.

11. Mitmekesisusega tegelemisel lasub põhiroll majandusel.

12. Haridusel on mitu tasandit ja nägu.

13. Laste ja kooli kultuuriline ning sotsiaalne kapital ei pruugi omavahel sobida.

14. Hariduspoliitikat ja -tegelikkust peaksid juhtima mõistus ja uurimistulemused (ingl evidence).

15. Peab arvestama lõhestava tehnoloogia (ingl disruptive technologies) mõjuga rakendamise väljavaadetele.

16. Tehnoloogial on potentsiaal muuta haridust.

17. Keskenduda tuleks iga indiviidi erakordsusele.

18. Õppe universaaldisain loob õppimiseks õiglased ja rahuldavad (ingl fair) võimalused.

19. Arendada tuleb varajase profülaktika ja sekkumise programme.

Võtmesõnadest määratleb autor kaasava hariduse sellisena, mis sobib õppijate võimete, huvide, väärtuste ja kogemustega, samuti vajadusega suhestuda oma eakaaslastega nende mitmekesisuses. Kaasav haridus on mitmetahuline mõiste, mis nõuab, et kõigi haridussüsteemi tasandite pedagoogid ja haridusjuhid peaksid silmas visiooni, õpperühma paigutamist, õppekava, hindamist, õpetamist, heakskiitu, juurdepääsu, tuge, ressursse ja eestvedamist (lk 11).

Mitmekesisusele lähenemise õiguslikuks aluseks pakub Mitchell John Rawlsi õiglase (ümber?)jaotamise teooria. Autor käsitleb lk-del 11-15 lühidalt John Rawlsi kitsas mõttes õnne-egalitaarsust, samuti libertaarsust, utilitaarsust ja Kanti mõistusega määratletud moraalipõhimõtteid. Veidi pikemalt peatub Mitchell John Rawlsi erisuspõhimõttel (ingl difference principle). Nimelt tuleks erisuspõhimõtte kohaselt õiglaselt otsustamiseks kujutleda end teadmatusloori 
taha, jättes eristavad tunnused arvestamata. Esmane kõigile rakenduv põhimõte olgu järgmine: kõigil on võrdsed õigused ja vabadused (nt kõne- ja usuvabadus). Erisuspõhimõtte järgi on lahknemine rangest võrdsusest lubatud juhul, kui jutuks olev ebavõrdsus tagab vähimate eelistega isikutele ühiskonnas parema majandusliku seisu kui täieliku võrdsuse oludes. Kahe põhimõtte konflikti korral ei tohi põhivabadusi ohverdada ei suurema võimaluste võrdsuse ega suurema majandusliku hüveolu nimel. Samas peab Mitchell John Rawlsi enda esitatud teooriast johtuvaid praktilisi soovitusi vastuolulisteks ja ebarealistlikeks. Nende hulka kuulub näiteks idee, et andeid tuleb igati arendada, kuid nende rakendamise hüved ei tohiks kuuluda asjaomasele indiviidile, vaid ühiskonnale.

Teiseks püüab Mitchell kriitiliselt suhestuda erinevate ökoloogiateooriatega (lk 15-19). Autor refereerib Mel Ainscow' jt võrdsusökoloogia (ingl ecology of equity) käsitlusi. Teooria kohaselt ei sõltu üksnes õpetajate ja koolide hariduspraktikast, millisel määral õpilaste kogemusi ja tulemusi hinnatakse õiglaselt. Seda mõjutab ka hulk vastastikmõjulisi protsesse: koolipiirkonna demograafia, elanikkonna ajalugu ja kultuur(id), sotsiaal-majanduslikud protsessid, mille tulemusel mõni piirkond on vaene ja teine jõukas, koondades erinevaid migrandirühmi. Mitchelli lugejal sobib silmata Urie Bronfenbrenneri ökosüsteemiteooriat, milles spiraali keskmes on laps, siis tulevad pere, klassiruum, kool, kogukond ja lõpuks - ühiskond.

Mitchell rõhutab, et igal maal toimib haridus omamoodi: aja- ja ruumikontekst mõjuvad nii sellele, kuidas mitmesuguseid erinevusi sotsiaalselt konstrueeritakse, kui ka sellele, kuidas asjaomased ühiskondlikud jõud omavahel võistlevad. Üle ilma on ühiskondade jaoks paras proovikivi leida tasakaal erinevuste tunnustamise ja ühtekuuluvusvajaduse vahel (lk 17).

Üks kaasamisdiskussiooni võtmeküsimusi leiab käsitlemist lk-del 28-29, kordudes võimete peatükis. Nimelt see, kas eri õppijarühmad vajavad eri ópistrateegiaid. Mitchell: ühelt poolt ,jah“, teisalt piiritletud „ei“. „Jah“ puudutab mõnda, eeskätt sügava nägemis- või kõnepuudega õppurit. „Ei“ korral lähtutakse arusaamast, et enamik vajab lihtsalt head õpetamist, teisisõnu, hulga mõjusate õpistrateegiate süsteemset, selget ja tõhusat rakendamist.

Ka teise põhiprobleemi lahendab Mitchell kirikuga keset küla. On's kaasamine tõenduspõhiselt mõjus? Vastus: tõenduspõhisusele lisaks tuleb silmas pidada filosoofiat ja teooriaid, nt inimõiguste, indoktrineerimise ja kaasamise puhul (lk 28). Sellele järgneb ülaltooduga sarnane täpsustus: mõned õpilasrühmad (raske intellekti-, nägemis- ja kõnepuudega õpilased) vajavad eristuvat õpet, kuid enamasti vajatakse vaid heatasemelist õpet. Ühes sõlmküsimuses taandub Mitchell erapooletuks refereerijaks, kirjutades, et „mõne autori väitel on vähe tõendeid puudespetsiifilise õppe kasulikkuse kohta. Seevastu on 
olemas kõigile kasulikke õppeviise, mida kohandatakse kognitiivsetele, emotsionaalsetele ja sotsiaalsetele võimetele ning kultuuritaustale“ (seals).

Käsilolevat neljandat tööstusrevolutsiooni, infotehnoloogiapööret puudutab Mitchell kahes pealtnäha vastandlikus vaates. Üks vaade on negatiivne. Lõhestavate tehnoloogiate kaudu kahanevad alaharitute väljavaated tööle rakenduda. Töötusrisk on suur madala sotsiaal-majandusliku staatusega peredest pärit, rahvusvähemusi esindavatele ja puudega lastele. (Muidugi võib samal ajal kaduda suure osa ühiskonna jaoks üleüldse töö kui täiskasvanuidentiteedi keskne tunnus.) Teisalt võib tehnoloogia tõhustada haridust, välja arvatud nende laste jaoks, kes jäävad n-ö valele poole digilõhet. Mitchell eelistaks näha üldist individualiseeritud ehk isikustatud (USAs personalized) õpet, sest riskirühmades on suuri sisemisi erinevusi. Isikustatud õpe järgib õpivajadusi, kohandudes õpieelistuste ja -huvidega, andes suuna diferentseerimisele ja individualiseerimisele (lk 29-31, vt Transforming ..., 2010).

Isikustatud õppe soodustaja on universaaldisain kui paindlikkus info esitamisel, õppurite reageerimis- ja kaasamisviiside valikul, ühtlasi tõkete eemaldamine õppest koos sobivate kohanduste, tugede ja raskustega, mille korral säilitatakse suured ootused kõigi suhtes. US Center for Applied Special Technology määratleb universaaldisaini kui õppevara ja tegevuse kujundamist viisil, mis tagab, et ka need õppurid, kellel avaldub olulisi erinevusi võimes näha, kuulda, kõnelda, liikuda, lugeda, kirjutada, mõista inglise keelt, osaleda, korraldada, kaasata ja mäletada, saavutavad seatud õppe-eesmärgid.

Bioloogilist ja sotsiaalset sugupoolt (ingl sex/gender) käsitlevas peatükis (lk 44-90) analüüsitakse poisiks, tütarlapseks ja muudeks variantideks olemise erijooni, tugevaid ja nõrku külgi, sugupooleks kujunemise bioloogilisi ja sotsiaalseid mõjureid ning sugupoole, rahvuse, sotsiaal-majandusliku staatuse (SMS), religiooni ja puude kaasmõju. Autor esitab soovitusi (tabel 2.1, lk 80) ühiskonna/valitsuse, haridussüsteemi, kooli ja klassi tasandil. Riskitegurite koos- ja kaasmõju olulise argumendi leiab Mitchell Steve Strandi hiljutisest uurimusest, kus uuriti 15000 Ühendkuningriigi 11-, 14- ja 16aastase õpilase edasijõudmist (lk 68-69, vt Strand, 2013). Nimelt kujunes Strandi uurimuses pilt ootuspärasest märgatavalt kirjumaks. 16aastaste Briti tüdrukute sooritus ületas 16aastaste Briti poiste oma, seejuures oli see lõhe oluliselt suurem Bangladeshi ja Kariibi päritolu õpilaste hulgas. Madala SMSiga poiste seas olid britid ja kariibid nõrgima sooritusega; madala SMSiga tüdrukute hulgas skoorisid kariibid kõrgemalt kui britid koos teiste vähemustega. Kõrge SMSiga õpilastel olid rahvuslikud erinevused väiksemad, kuid siiski skoorisid India päritolu poisid brittidest kõrgemalt ja kariibid madalamalt. Absoluutnäitajatelt skoorisid nõrgalt kolm madala SMSiga alarühma: (mustad) kariibid, valged briti poisid ja tüdrukud. 
Ühiskondliku klassikuuluvuse / perekonna SMSi (kaas)mõjule pühendatud kolmandas peatükis loetleb Mitchell seoseid vaesuse ja edutuse vahel, välistamata erandlikke säilenõtkeid juhtumeid ning kaaludes võimalusi neid seoseid vähendada. Nimelt toetab autor riigi/ühiskonna tasandil progresseeruvat omandimaksu Piketty vaimus ja äraelamiseks piisavat kodanikupalka (ingl living wages) David Berlineri vaimus. Kooli tasandil vähendavad riske mõjus juhtimine, perede kaasamine, keskendatus kirja- ja arvutusoskusele, SMSi, sugupoole ja rahvuse vahelise seose silmaspidamine, õpiedu järjepidev seire, toetav koolikultuur ja ohustatud lastele lisatoe pakkumine. Klassi tasandil soovitatakse rakendada kõigile sobivat õppekava, tagada kõigile võrdne juurdepääs, seada suuri, kuid realistlikke ootusi ja kasutada tõenduspõhiseid õppeviise.

Neljas peatükk on pühendatud rassi-, rahvuse- ja kultuurierinevustele. Probleemidele pakutakse taas kõigi nelja tasandi lahendusi, kujundamaks hariduse abil tasakaalu eri rahvuste ühtsuse ja mitmekesisuse vahel. Ebasoodsate tendentsidena nimetab Mitchell vähemusrahvusi n-ö oma koolidesse koondavaid elamurajoone ning vähemuste ala- või üleesindatust erivajadustega óppijate seas. Paradoksiks peab ta aga valgete üleesindatust nii USA andekusprogrammides kui ka apartheidiaegse Lõuna-Aafrika eripedagoogika rüpes. Rassilõhet ületava hariduspoliitika ainsa edukusnäitena viitab Mitchell nn magnetkoolidele USA slummides, mille eriprogrammid osutusid külgetõmbavaks ka naabruse (valgele) keskklassile. Selle peatüki kohati raskepärane lauseehitus raskendab aga sõnumi täielikku mõistmist.

Võib-olla pakub lugejale huvi siinkirjutaja poolt teisest allikast leitud paralleel, olgugi et see ei puuduta erivajadusi. Nimelt leiab Iisraelist Jeruusalemma külje alt Betaania kreekakatoliku kiriku tütarlastekooli. Kool on araabiakeelne, enamik õpilasi on moslemid (kristlased moodustavad vähemuse). Kool määras kaheks tunnivabaks päevaks reede (moslemi meeste pealelõuna-ühispalve päev) ja pühapäeva (kristlased), kuid asukohariigis endas puhatakse sabatilaupäeval. Alates viiendast klassist õpitakse seal teise võõrkeelena vene keelt (Pikkov, 2014).

Viiendas peatükis käsitleb Mitchell religioosseid ja veendumuserinevusi, sh potentsiaalset konflikti vanemate valitud religiooni (eelmises peatükis päritolukultuuri) või vastava hariduse ja laste valikuvabaduse vahel. Järgnevalt esitan mõned soovitused kokkuvõtlikust tabelist lk-1 234. Riigi/ühiskonna tasandil kõlab pakutust kõige uudislikumana mõte vähendada koolis usunditevahelist disproportsiooni. Haridussüsteemi tasandil tuleks õpetada usundeid/ usundilugu ühtegi usundit teistele eelistamata. Keerukam on põimida nõuet austada vanemate poolt lastele valitud usu- ja moraaliõpetust laste enesemääramisvabadusega - kooskõlas õppurite kasvamise ja küpsemisega. Koolid vältigu 
kreatsionismiõpet ja negatiivseid usundistereotüüpe õppevaras. Klassiruumis valitsegu sallivus, sealhulgas õpetaja maailmavaatest tulenevate erinevuste suhtes. Mõnevõrra jääb õhku autori püüd jagada juhiseid, kuidas vältida indoktrineerimist ja ajupesu. Alapeatükk maooridest lk-del 253-254 haakub võimete teemaga nõrgalt, ka pealiskaudne Lähis-Ida lõik sobinuks pigem kultuurierinevusi iseloomustama.

Kuuendas peatükis eristab Mitchell kehalisi, intellektuaalseid ja isiksuslikke võimeid. Autor pühendab rohkesti täheruumi HEV-teemale, jättes küll erivajadustest ruumipuudusel kajastamata eri- ja üldandekuse. HEV-praktikas jätkuv meditsiinilis-psühholoogiline liigitus pälvib autori hinnangul õigustamatult rohkem tähelepanu kui mõjus õpe, mille tõhusa rakendamise eelduse näiteks toob ta USA sekkumisvastuse malli. Mitchell ei jäta osutamata ka puudestatistika paradoksile. Nimelt pole hariduslike erivajaduste statistika riigiti võrreldav, ometi esitatakse kaasamisdiskursuses ikka ja jälle edetabeleid. Omapärasena, kuid küllalt edukana toob Mitchell esile Jaapani kooli, kus ei keskenduta erinevustele, vaid hinnatakse eeskätt püsivat püüdlikkust, vähem sooritust (lk 251-252).

Mitchell osutab, et HEV-õpilasele kulub 2-4kordne tavaõpilase pearaha. Riigiti rakendatakse kolme HEV-õppe rahastamise malli: nõudlus-, pakkumis- ja väljundipõhist. Esimene võib motiveerida valdkonna medikaliseerumist; teine seab piirmäära kas õppurite või eraldiste osakaalule koguarvust või -kulust (USAs võib 12\%-1 õpilastest kvalifitseerida õpiraskusi). Väljundipõhise rahastusega võib põhjustada väärastumise selles mõttes, et edukalt õpetanud kool kaotab lisarahastuse (lk 274). Võimete peatükki näib mõnevõrra kammitsevat autori hirm korrata oma varasemaid teoseid konfliktidest ja kaasavast eripedagoogikast (mõlemad aastast 2014).

Ühe võtme David Mitchelli optimismi mõistmiseks leiab leheküljelt 267: „... aktsepteerides kaasamisretoorika kriitikute argumente, tuleb ometi silmas pidada, et on enneaegne hinnata kaasamise mõjusust, kuni kaasamist pole rakendatud parimal võimalikul viisil“ (ingl in a fully comprehensive way). Kas ei meenuta see uusmarksiste, kelle hinnangul ootab Marxi teooria alles oma parimat võimalikku rakendust?

Käsitluse rahvusvaheline ehk võrdlev-pedagoogiline haare on mõnes peatükis tugevam, sh eurokesksem, teisal lahjavõitu. Katse hõlmata USA näiteid ühena teiste kõrval jääb paratamatult pealiskaudseks, teemakohaselt oodanuks rohkemat ka teiselt kuninganna alamalt - Kanadalt.

Raamat on ja ei ole ka lugejasõbralik. Tekst katab lehekülgi püsttulpadeta, seda liigendavad ainult tihedad nummerdatud alapealkirjad. Allikaviited on tekstis pisitillukese numbriga, mis lugemist ei häiri. Allikaloendeid endid pole aga iga peatüki järelt just ülearu kerge leida. Rohked soovitused võetakse iga 
peatüki lõpus kokku tabelis, liigendades need riigi (ühiskonna), koolipiirkonna, kooli ja klassi tasandi kaupa. Koloriidiks on autor lisanud läbivalt maoori, vähem ka jaapanikeelseid sõnu. Alla miljoni kõnelejaga maoori on üks 103st Google'i tõlkekeelest; raamatust leiame whānau, hapu, iwi, rangatiratanga (lk 181, 253-254). Tore on omaette korrata järele ka sõnu noryokusa, tsumikasane, kuro ja ishokemmei, mille leiab lk-lt 251.

Peatükkide akadeemilist teemakäsitlust isikustatakse, alustades neid mõtisklusega sellest, millal ja kelle või millega on talupoisina möödunud sajandi keskel üles kasvanud autor oma lapsepõlves või eluteel või esivanemate kaudu kokku puutunud. Pole ehk üllatav, et võimetest olid poisipõlves esil kiirus ja osavus, et esimene kohatud mittevalge inimene oli klassikaaslasest poolmaoori või et külas nappis poissjuulasid. Õpime tundma Uus-Meremaad kui XIX sajandi saksa ja inglise kolonistide (peaaegu teostunud) unelmat klasside ja seisusteta ühiskonnast.

Oma kolmanda raamatu järel nii kodupinnal kui ka laias ilmas kaasava õppe staaresinejaks tõusnud autori temaatiline haare on laienenud. Mitchell jätkab osavalt mängu moesõnadega, et osutada asjaomaste ideede põhimõttelisele rakendatavusele, kui selleks piisavalt pingutada. Pingutada väga korralikult ja õige mitmel rindel. Tundub, et uut raamatut võib hinnata mõõdukalt tempereeritud utoopiana teel täielikult isikustatud õppe poole. Eesti keelde tõlkimiseks ei rutta ma raamatut soovitama, kuid peale Tartu ülikooli raamatukogu peaks eksemplarid soetatama kahte Tallinna ja ühte Narva raamatukogusse, niisama kui e-väljaandena mõnekümne haridusametniku ja õppejõu tööarvutisse.

Võib kaaluda, kas David Mitchell kuulub nende tipptasemel haridusedendajate sekka, kes alustavad HEV-õpilastega, laiendades edu korral haaret, nagu seda on teinud nt Leonid Zankov ja Siegfried Engelmann. Eestis on/oli selline potentsiaal Karl Karlepi emakeele arendusmetoodikal ... Rangatiratangat meile kõigile!

\section{Kasutatud kirjandus}

Pikkov, H. (2014). Minu Jeruusalemm: kaameraga kloostris. Tartu: Petrone Print.

Strand, S. (2013). Ethnicity, gender, social class and achievement gaps at age 16: Intersectionality and 'getting it' for the white working class. Research Papers in Education, 29(2), 131-171. https://doi.org/10.1080/02671522.2013.767370

Transforming American education: Learning powered by technology. National educational technology plan (2010). Washington: US Department of Education, Office of Educational Technology. 